\title{
Patient education to encourage graded exercise improved physical functioning in chronic fatigue syndrome
}

Powell P, Bentall RP,Nye FJ, et al. Randomised controlled trial of patient education to encourage graded exercise in chronic fatigue syndrome. BMJ $2001 \mathrm{Feb}$ 17;322:387-90.

\section{QUESTION: In patients with chronic fatigue syndrome (CFS), how effective is an education programme in encouraging graded exercise and in improving physical function?}

Design

Randomised (unclear allocation concealment*), unblinded,* controlled trial with 12 months follow up.

Setting

Chronic fatigue clinic and an infectious diseases outpatient clinic in the UK.

\section{Patients}

148 patients (mean age $33 \mathrm{y}, 78 \%$ women) who had the Oxford criteria for CFS and a score of $<25$ on the physical functioning subscale of the Short Form 36 questionnaire. Exclusion criteria were having further physical investigations or taking other treatments; a history of psychotic illness, somatization disorder, eating disorder, or substance abuse; or being confined to a wheelchair or bed.

\section{Intervention}

Patients were allocated to 1 of 4 groups. 34 patients were allocated to standardised medical care (control group). Patients allocated to an intervention all received 2 individual treatment sessions and 2 telephone follow up calls, supported by an educational package describing the role of disrupted physiological regulation in fatigue symptoms and encouraging home based graded exercise. The minimum intervention group $(n=37)$ had no further treatment, the telephone group $(n=39)$ received an additional 7 follow up calls, and the maximum group $(\mathrm{n}=38)$ received an additional 7 face to face sessions over 4 months.

\section{Main outcome measures}

The primary outcome was clinically important improvement at 1 year (a score of $\geqslant 25$ or an increase of $\geqslant 10$ from baseline on the physical functioning scale). Secondary outcomes included changes in fatigue, sleep, disability, and mood.

\section{Main results}

Analysis was by intention to treat with all patients included. More patients in the intervention groups met the criteria for clinical improvement than in the control group (table), with no difference among the intervention groups. Fatigue, sleep, disability, and mood improved in the 3 intervention groups but not in the control group.

\section{Conclusion}

In chronic fatigue syndrome, patient education to encourage graded exercise led to improved physical functioning.

\section{*See glossary.}

Improvement at 1 year for minimum (MI), telephone (T), and maximum (MA) intervention $v$ control treatment in the chronic fatigue syndrome $\dagger$

\begin{tabular}{llll} 
Comparisons & Improvement & RBI (95\% Cl) & NNT (CI) \\
Ml $v$ control & $70 \% v 6 \%$ & $1095 \%(260$ to 4270$)$ & 2 (2 to 3) \\
\hline T $v$ control & $69 \% v 6 \%$ & $1078 \%(254$ to 4205$)$ & $2(2$ to 3$)$ \\
\hline MA $v$ control & $68 \% v 6 \%$ & $1063 \%(250$ to 4158$)$ & 2 (2 to 3) \\
\hline $\begin{array}{l}\text { Thbbreviations defined in glossary; RBI, NNT, and Cl calculated from data in } \\
\text { article. }\end{array}$
\end{tabular}

\section{COMMENTARY}

5 randomised controlled trials (RCTs) of rehabilitative approaches for CFS in secondary care have been previously published. The first trial by Lloyd $e t$ al found that brief CBT was no better than medical care. ${ }^{1}$ Subsequent trials using more intensive treatment found substantial benefits over both usual care and relaxation therapy. ${ }^{2}{ }^{3}$ RCTs of supervised simple graded exercise therapy (GET)-both of which showed some, although less, benefit-have also been published. ${ }^{5}$ These trials were all of intensive therapy given by skilled practitioners in special centres. If therapy was better targeted, could less intensive treatment work? Could less skilled therapists deliver effective treatment? Are patient self help groups as effective as these treatments?

Powell et al addressed the value of better targeted, but briefer, treatment. Although called "educational," the treatment was similar to CBT and GET but emphasised providing a physiological rationale for rehabilitation. The results were remarkable: although the usual care group changed minimally, all 3 intervention groups, even the minimal one, improved substantially. This trial suggests that a brief intervention can work, perhaps because it used a rationale that was consistent with patients' own understanding of their illness.

Prins et al's well designed study was marred only by limited patient adherence to treatment and attrition in follow up. This study showed that CBT could offer substantial benefit over usual care, even when delivered by non-experts in non-specialist centres. Interestingly, support groups satisfied patients but did not improve outcomes.

What can we conclude? 7 RCTs now exist using rehabilitative approaches for CFS, and 6 have shown benefits. Although the names of the interventions have varied, all are forms of rehabilitation. ${ }^{6}$ However, important caveats are noted: the total number of patients in these RCTs remains relatively small. Patients who cannot attend outpatient facilities have been excluded. Although most patients achieve improved functioning, they often continue to report excessive fatigue, and some patients do not respond at all. Finally, some patient organisations will not welcome these new findings. The reasons given are continued on next page 


\section{Cognitive behaviour therapy reduced fatigue severity and functional impairment in chronic fatigue syndrome}

Prins JB, Bleijenberg G, Bazelmans E, et al. Cognitive behaviour therapy for chronic fatigue syndrome: a multicentre randomised controlled trial. Lancet 2001 Mar 17;357:841-7.

\section{QUESTION: In patients with the chronic fatigue syndrome (CFS), how effective is cognitive behaviour therapy (CBT) in reducing fatigue and functional improvement?}

\section{Design}

Multicentre, randomised \{allocation concealed*\}t, unblinded,* controlled trial with 8 months follow up (follow up at 14 mo was $<80 \%$ ).

\section{Setting}

3 mental health settings in the Netherlands: 2 based in university medical centres and 1 in a mental health institute.

\section{Patients \\ 278 patients between 18 and 60 years of age (mean age 37 y, $79 \%$ women) with the US Centers for Disease Con- trol and Prevention criteria for CFS, a score of $\geqslant 40$ on the fatigue severity subscale of the checklist individual strength (CIS), and a score of $\geqslant 800$ on the sickness impact profile. Exclusion criteria included pregnancy and previous or current participation in CFS research.}

\section{Intervention}

93 patients were allocated to CBT (sixteen $1 \mathrm{~h}$ sessions over $8 \mathrm{mo}$ ), 94 to guided support groups (eleven $1.5 \mathrm{~h}$ meetings over $8 \mathrm{mo}$ ), and 91 to the control group (no intervention).

\section{Main outcome measures}

The primary outcomes were fatigue severity and functional impairment. Clinical improvement was defined as a reliable change index $>1.64$ and a fatigue severity score $\leqslant 36$, showing that the patient had moved to the range of a healthy person.

\section{Main results}

At 8 months, 241 patients (89\%) had complete data. This dropped to $73 \%$ at 14 months. At 8 months of follow up and for both primary outcomes, CBT was more effective than both guided support and no treatment with no difference between the latter 2 groups. More patients in the CBT group met the criteria for clinical improvement for CIS fatigue severity and self rated improvement in fatigue (table). Secondary outcomes at various time points were statistically different, but follow up was $<80 \%$.

\section{Conclusion}

In the chronic fatigue syndrome, cognitive behaviour therapy reduced fatigue and functional impairment.

*See glossary.

$\nmid$ Information provided by the author.

Source of funding:

Health Insurance

Council.

For correspondence: Ms J B Prins,

Department of Medical Psychology, University Medical Centre

Nijmegen, $P O$ Box

9101, $6500 \mathrm{HB}$

Nijmegen, the Netherlands. Fax +31 243613425 .

Improvement at 8 months for cognitive behavior therapy (CBT), guided support (GS), and control treatment $(C)$ in the chronic fatigue syndrome $\ddagger$

\begin{tabular}{|c|c|c|c|c|}
\hline Outcomes & Comparison & Improvement & RBI $(95 \% \mathrm{Cl})$ & NNT (Cl) \\
\hline \multirow[t]{2}{*}{$\mathrm{CIS}$ fatigue severity } & CBT $v$ GS & $33 \% \vee 13 \%$ & $160 \%$ (38 to 402 ) & $5(4$ to 14$)$ \\
\hline & $\mathrm{CBT} \vee \mathrm{C}$ & $33 \% \vee 13 \%$ & $154 \%$ (35 to 389 ) & $6(4$ to 15$)$ \\
\hline \multirow{2}{*}{$\begin{array}{l}\text { Self rated improvement } \\
\text { in fatigue }\end{array}$} & CBT $v$ GS & $57 \%$ v $17 \%$ & $236 \%$ (99 to 489 ) & $3(2$ to 5$)$ \\
\hline & CBT $v \mathrm{C}$ & $57 \%$ v $30 \%$ & $93 \%(31$ to 189$)$ & 4 (3 to 9$)$ \\
\hline
\end{tabular}

‡CIS = checklist individual strength. Other abbreviations defined in glossary; RBI, NNT, and Cl calculated from data in article.

\section{COMMENTARY-continued from previous page}

(1) the treatments are not a cure; (2) success of psychological treatment implies that CFS is a psychological disorder; and (3) such treatments can be harmful. Adverse effects have rarely been reported in these trials but should be in future trials.

We now need large pragmatic trials that evaluate the utility of rehabilitative approaches in routine practice and explanatory trials to clarify which treatment components are most potent. Finally, we need to establish the place for rehabilitation in the medical care of CFS and related syndromes, and we need to ensure that it is delivered in a form acceptable to patients. These trials are useful steps along that road.

Michael Sharpe, MD University of Edinburgh Edinburgh, UK

1 Lloyd AR, Hickie I, Brockman A, et al. Immunologic and psychologic therapy for patients with chronic fatigue syndrome: a double-blind, placebo-controlled trial. Am J Med 1993;94:197-203.

2 Deale A, Chalder T, Marks I, et al. Cognitive behavior therapy for chronic fatigue syndrome: a randomized controlled trial. Am J Psychiatry 1997;154:408-14.

3 Sharpe M, Hawton K, Simkin S, et al. Cognitive behaviour therapy for the chronic fatigue syndrome: a randomised controlled trial. BMJ 1996;312:22-6.

4 Fulcher KY, White PD. Randomised controlled trial of graded exercise in patients with the chronic fatigue syndrome. BMJ 1997;314:1647-52.

5 Werden AJ, Morriss RK, Mullis R, et al. Randomised double-blind, placebo-controlled treatment trial of fluoxetine and graded exercise for chronic fatigue syndrome. Br J Psychiatry 1998;1 172:485-90.

6 Sharpe M. Rehabilitative treatments for CFS: cognitive behavioural and graded exercise therapies. Ballieres Clinical Psychiatry 1997;3:511-536. 